\title{
An epidemiological survey of rheumatic fever and rheumatic heart disease in Sahafa Town, Sudan
}

\author{
Siddig Ibrahim-Khalil, Mohamed Elhag, Elnagi Ali, Fatih Mahgoub, Suzan Hakiem, Nadia \\ Omer, Soheib Shafie, Elsadig Mahgoub
}

\begin{abstract}
Study objective-The aim was to determine the prevalence of rheumatic fever and rheumatic heart disease and to initiate a programme of secondary prophylaxis in Sahafa Town, Sudan.
\end{abstract}

Design-The study was a prospective case finding survey, carried out by a specially trained team headed by a cardiologist.

Setting-The study involved high risk school children (5-15 years of age) from Sahafa Town in the period 1986-1989.

Subjects-A total of 13332 children on the school registers (7892 boys and 5430 girls) were examined generally and specifically for evidence of rheumatic fever or rheumatic heart disease.

Main results-Out of the 13322 children screened 351 were suspected cases and 146 were confirmed cases of rheumatic fever or rheumatic heart disease. The prevalence rates for all ages were $10 / 1000$ for boys and $14 / 1000$ for girls. The overall prevalence rate of the whole programme area was $11 / 1000$, prevalence of rheumatic fever was $8 / 1000$, and prevalence of rheumatic heart disease was $3 / 1000$. The prevalence rate was significantly increased among the inner town inhabitants $(15 / 1000)$ compared to the outer town inhabitants $4 / 1000(p<0.001)$. Monthly prophylactic benzathine penicillin in a dose of $1200000 \mathrm{IU}$ was given to both suspected and confirmed cases. Penicillin coverage rate was $72 \%$.

Conclusions-Rheumatic fever continues to be a serious health problem. With economic pressures causing impending change in socioeconomic conditions in most Third World countries in the immediate future, rheumatic fever will continue to have a high prevalence rate and rheumatic fever and rheumatic heart disease prevention programmes will remain a central goal.

f Epidemiol Community Health 1992; 46: 477-479

Although rheumatic heart disease has shown a dramatic decline in most of the developed countries, ${ }^{1-3}$ it continues to be a serious health problem in Third World countries, due partly to poor environmental hygiene and low socioeconomic standards, and partly to the lack of comprehensive prevention programmes. ${ }^{4-6}$ In the Sudan, rheumatic heart disease in still the most frequent cause of heart disease in the 5-30 year age group, and it accounts for $36 \%$ of the total hospital admissions for cardiovascular disease. ${ }^{7}$ It is seen in children as young as 4 years, and is frequently complicated by congestive heart failure and pulmonary hypertension, making surgical treatment imperative at an early age.

The available data on rheumatic heart disease in the Sudan are based mainly on hospital admission records ${ }^{8}$ which do not give an accurate picture of the incidence of the disease. For this reason, we decided to embark on a detection and prevention programme, as part of the World Health Organization (WHO) Global Rheumatic Heart Disease Prevention Programme.

The general objective of this programme is to reduce the incidence of acute rheumatic fever (especially relapses) and its cardiac sequelae in the programme area, by administering regular secondary preventive measures in the case of susceptible patients, and by promoting effective early treatment of streptococcal sore throat. The specific objective was to carry out a case finding prevalence survey in order to determine the prevalence of rheumatic fever and rheumatic heart disease among school children of 5-15 years in Sahafa Town, and to initiate and maintain a programme of regular secondary prophylaxis. ${ }^{9}$ This paper describes phase I of the programme, which is being carried out in Sahafa Town. Phase II is to be nationwide programme, starting in the early 1990s.

Sahafa Town was believed to have the highest incidence of rheumatic fever and rheumatic heart disease in Khartoum, judging by the hospital records. The town was created in the mid-sixties on the southern outskirts of Khartoum, and by 1986 it had an overall population of at least $300000,30 \%$ of whom were below the age of 15 years. $^{10}$ Its population consists of two fairly distinct categories, the original inhabitants, who have been living in the inner town area since the town was founded, and the newer inhabitants who came to settle in the outer town areas following the drought that struck the country in the early 1980s. Most of the original inner inhabitants are skilled workers, with a small middle class, and most of the newer town inhabitants are unskilled workers living in poor housing conditions.

\section{Methods}

This study was conducted in the primary schools of Sahafa Town in the period 1986-1989, and arrangements were made to examine all school children aged between 5 and 15 years. Teachers and pupils were given talks, and posters were put up in the schools in order to inform them thoroughly of the aims of the programme. The screening survey was carried out by a team headed by a cardiologist and consisting of eight hospital doctors, six health auxiliary staff (including social 
workers and health visitors), and six nurses. The doctors had all been trained at the cardiology department of the Shaab Hospital for at least two years, and the rest of the team were all given a special two weeks training course.

A total of 13322 children on the school registers, 7892 boys and 5430 girls, were examined in an office at the school specially prepared for the purpose, 8263 of them in the Central, West, and East Sahafa inner town areas, and the remaining 5059 in the outer town areas, during the period from November 1986 to November 1989. Each child was given a general and a cardiovascular examination by a doctor, assisted by an auxiliary health worker or a nurse. All the children showing an abnormal heart condition, defined as cardiac murmurs, cardiomegaly, or arrhythmia, were re-examined a day or two later in hospital by a cardiologist, and received an electrocardiogram, a chest $x$ ray, and whenever needed an echocardiogram, to confirm or refute the diagnosis. All school absentees were traced and those able to come to school were examined during the screening time for that school, and those unable to come to school because they were ill were examined later in hospital. By the end of the survey, all the children on the official school registers had been examined.

The confirmed diagnosis was recorded on the initial record form (WHO study K $5 \cdot 10$ ), together with the following data: date of birth, address, socioeconomic group, New York Heart Association (NYHA) functional classification, other diagnosed conditions, year of onset of rheumatic fever, preceding history of throat infection, duration of valvular disease, history of prophylactic regime, and number of attacks of rheumatic fever. Rheumatic fever was diagnosed according to the Jones criteria, ${ }^{11}$ and cases which partly fulfilled the criteria were considered suspected cases of rheumatic fever.

Children with confirmed or suspected diagnosis of rheumatic fever or rheumatic heart disease were immediately started on a programme of treatment, and were given an intramuscular dose of 1200000 IU of benzathine penicillin every four weeks after that. The penicillin coverage rate (that is, the number of those who actually received penicillin as percentage of those who ought to have received it) was recorded for the whole programme area.

\section{Results}

Table I shows the total number of cases screened during phase I of the programme. The inner town consists of Sahafa Central, East, and West areas, and the outer town consists of Gabra, Id Hussein, and Mayo areas. The target population of 18977 had been calculated from population estimate figures provided by the Sahafa Town Council, and the 13322 screened represented only $70 \%$ of that target population. The missing $30 \%$ were thought to be children who were not attending school at all for various reasons. The prevalence rate for rheumatic fever and rheumatic heart disease was found to be higher among the inner town inhabitants $(15 / 1000)$ than among the outer town inhabitants $(4 / 1000)(\mathrm{p}<0.001)$.

Out of the 13322 children screened during the programme, 351 were suspected cases of rheumatic fever and rheumatic heart disease, of whom 194 were girls, giving a male to female (M:F) ratio of $1: 1 \cdot 2 ; 146$ were confirmed cases of rheumatic fever and rheumatic heart disease, of whom 85 were girls (M:F ratio 1:1.4). The prevalence rate among girls was $14 / 1000$ and among boys $10 / 1000$.

The prevalence rate for the whole programme area was $11 / 1000$, the prevalence of rheumatic fever was $8 / 1000$, and the prevalence of rheumatic heart disease was $3 / 1000$.

Different types of valvular lesions were found during the survey, the most common being mitral regurgitation ( $65 \%$ of all the lesions), followed by mitral stenosis ( $43 \%$ of all lesions). Combined mitral and aortic valve lesions accounted for only $4 \%$ of lesions.

Out of 146 children with rheumatic heart disease, $90 \%$ were graded as NYHA functional grade $1,7 \%$ as grade II, and $3 \%$ as grade III. The grade III cases received inpatient treatment. A previous history of throat infection was given by $46 \%$ of the cases. Benzathine penicillin coverage was expected to be more than $80 \%$, but was actually noted to be $72 \%$.

\section{Discussion}

Table II shows the prevalence rate of rheumatic heart disease in surveys in five countries. Developing countries have high prevalence rates, while in countries with high socioeconomic status, for example the USA ${ }^{13}$ and Japan, ${ }^{14}$ the disease has virtually disappeared. The rate in Sudan is one of the highest among the developing countries. ${ }^{15}$ The low prevalence rate in the outer town children $(4 / 1000)$ compared to the inner town children (15/1000) was unexpected, since the housing and sanitary conditions in the outer town were poor. The explanation may be that the outer town people had been staying in less crowded rural housing conditions until only a few years previously, and had settled in the outer town only during the previous three years. Their rheumatic fever and rheumatic heart disease prevalence rates may well rise the longer they stay in the overcrowded housing conditions of the outer town. An observation which requires explanation is the male to female ratio of $1: 1.2$ which is less than that reported in other countries. ${ }^{6} 15$ However, Shanker in India has found rheumatic heart disease to be equally common between the two sexes. ${ }^{19}$
Table I Cases screened during phase I of the programme.

\begin{tabular}{|c|c|c|c|c|c|c|c|}
\hline \multirow[b]{2}{*}{ Area } & \multirow[b]{2}{*}{$\begin{array}{l}\begin{array}{l}\text { Total target } \\
\text { population }\end{array} \\
\end{array}$} & \multirow[b]{2}{*}{$\begin{array}{l}\text { Actual number } \\
\text { screened }\end{array}$} & \multicolumn{2}{|c|}{$\begin{array}{l}\text { Cases } \\
\text { suspected }\end{array}$} & \multicolumn{2}{|c|}{$\begin{array}{l}\text { Cases } \\
\text { confirmed }\end{array}$} & \multirow{2}{*}{$\begin{array}{l}R F+R H D \\
\text { prevalence } \\
\text { per } 1000\end{array}$} \\
\hline & & & $R F$ & $R H D$ & $R F$ & $R H D$ & \\
\hline Sahafa inner town & 11177 & 8263 & 128 & 63 & 109 & 16 & 15 \\
\hline Sahafa outer town & 7800 & 5059 & 57 & 103 & 1 & 20 & 4 \\
\hline
\end{tabular}

$\overline{\mathrm{RF}}=$ rheumatic fever; $\mathrm{RHD}=$ rheumatic heart disease 
Table II Prevalence rates (PR) for rheumatic heart disease in five different countries

\begin{tabular}{llllc}
\hline Place of survey & Year & No of cases screened & $\begin{array}{l}\text { Age range } \\
\text { (years) }\end{array}$ & $P R / 1000$ \\
\hline Nigeria $^{5}$ & 1972 & 12755 & $6-12$ & $0 \cdot 3$ \\
India $^{18}$ & $1972-75$ & 24779 & $5-15$ & 2 \\
Soweto $^{6}$ & 1972 & 12050 & $7-18$ & $7 \cdot 1$ \\
Egypt $^{55}$ & 1973 & Primary school children & $5-15$ & 10 \\
Sudan & $1986-98$ & 13322 & $5-15$ & 11 \\
\hline
\end{tabular}

Sudan's high prevalence rate seems to have evolved during the last 50 years. In 1937, rheumatic heart disease formed only $5 \%$ of the total hospital admissions for cardiovascular disease in Khartoum, but by 1945 , the figure had risen to $14 \%$, by 1960 to $26 \%{ }^{16}$ and by 1984 to $36 \%{ }^{7}$ During this same period the population of Khartoum increased from 180000 in the 1930 s to 1830000 in 1984

The rapid increase in population has disrupted the existing health and environmental hygiene structures. Most of the new outer town inhabitants are living in poor and overcrowded housing. Overcrowding has also been a feature of school classrooms, as schools have expanded their intake to accommodate an increasing number of school age children. The average class size is now $60-65$. Overcrowding in classrooms is another cause of streptococcal cross infection.

During the survey, it became clear that if our diagnosis of rheumatic fever were based on Jones's criteria, then a large number of children would be excluded. For example, polyarthralgia and soft systolic murmur (grade I-II) in the left sternal border was detected in 390 children out of 13322 , and $32 \%$ of them gave a previous history of throat infection. A similar situation was reported in the Soweto study. We described this group as suspected cases of rheumatic fever. It is clear that such children need careful follow up to see whether they develop carditis or subsequent valvular disease. The benzathine penicillin coverage rate was expected to be above $80 \%$, but it was only $72 \%$. This was due mainly to unavailability of the drug, a history of an allergic reaction to the drug, and to the children's fear of the pain of the injection.

Rheumatic fever is a socioeconomic disease with prevalence increasing directly with poverty, malnutrition, overcrowding, and poor housing. The financial burden of treating cases of rheumatic heart disease both medically and surgically is enormous if compared to health budgets in most developing countries. Those countries must also face the problems of curtailment of government expenditure, devaluation of currency, and a general reorientation of the economy towards reducing imports and promoting exports. ${ }^{17}$ With the national debt repayments still outstanding, it will take some time to achieve the necessary improvement in socioeconomic standards and living conditions. This means that, for the immediate future, prevention is the only feasible way of reducing the rheumatic heart disease prevalence rate.

This study was funded partly by the World Health Organization. The author thanks Professor $\mathrm{H}$ TunstallPedoe, Director of the Cardiovascular Epidemiology Unit at Ninewells Hospital and Medical School, Dundee, for reading the manuscript and making valuable suggestions.

1 Sivers J, Hall P. Incidence of acute rheumatic fever. $\mathrm{Br}$ Heart f 1971; 33: 833-56.

Gardis L. The virtual disappearance of rheumatic fever in the United States: lessons on the rise and fall of disease. the United States: lessons on

3 Mack A, Land MA, Bisro AL. Acute rheumatic fever, a vanishing disease in suburbia. $\mathcal{F A M A}$ 1983; 249: 895-8.

4 Community control of rheumatic heart disease in developing countries. I. A major public health problem. WHO Chron 1988; 34: 336-46.

5 Ogunbi O, Fadahunsi H, Ahmed I. An epidemiological study of rheumatic fever and rheumatic heart disease in Lagos. I Epidemiol Community Health 1978; 32: 68-71.

6 Mclaren MJ, Hawkins DM, Koornhof HJ. Epidemiology of rheumatic heart disease in black school children of Soweto, Johannesburg. BMF 1975; iii: 474-8.

7 Khalil SI, Elsamani EZ, Dafalla G, Kazam E. Patterns of cardiovascular disease in Sudan: hospital load and recent cardiovascular disease in Sudan: hospit

8 Ismail SA, Gabir MH. Observation on rheumatic heart disease in Sudan. Trans R Soc Trop Med Hyg 1970; 64: disease

9 Rheumatic fever and rheumatic heart disease prevention programme in Sudan: plan of action. Khartoum: Ministry of Health, 1986

10 Sudan Annual Statistical Report. Khartoum: Government of Sudan, Ministry of Health, 1982.

11 Duckett-Jones $\mathrm{T}$. The diagnosis of rheumatic fever. $\mathcal{F} A M A$ 1944; 126: 481-4.

12 WHO Technical Report Series No 764 (Rheumatic fever and rheumatic heart disease. Report of WHO study group). Geneva: WHO, 1988.

13 Smith JN. The detection of heart disease in children. Circulation 1965; 32: 956-61.

14 Hiokawa Y. Present status of rheumatic fever and rheumatic heart disease in Japan. In: Hayasa S, Muras S, eds. heart disease in Japan. In: Hayasa S, Muras S, eds.
Cardiology. Amsterdam: Excerpta Medica, 1979: 517-21.

15 Community control of rheumatic heart disease in developing community control of rheumatic heart disease in

16 Halim AM, Jacques JE. Rheumatic heart disease in Sudan. Br Heart F 1961; 23: 383-5.

17 World Bank. Sub-Saharan Africa; from crisis to sustainable growth. A long-term perspective study. Washington DC: World Bank, 1989.

18 Nair DV. Kabir HA, Thankan S. Epidemiological survey of rheumatic heart disease in school children at Alleppey. Indian Heart $尹$ 1980; 32: 65-71.

19 Shankar PS. Cardiovascular disease; its morbidity and mortality in Northern Mysore State. Indian Heart $\mathcal{F} 1968$; 20: 423 . 